\title{
Conjunctive Adverbials in Chinese ESL Postgraduates' Expository Writing
}

\author{
Xuehua An \\ Dalian University of Technology, China \\ Mingying $\mathrm{Xu}$ \\ Dalian University of Technology, China
}

\begin{abstract}
Conjunctive adverbials perform important cohesive and connective functions in discourse. Logically linking sentences into paragraphs and paragraphs into an essay might impose great challenge for ESL learners. This paper investigated the use of conjunctive adverbials in the expository writings of Chinese postgraduate students. Learner corpus of $\mathbf{3 6 5}$ pieces of writings was compiled for analysis. The findings indicated that the participants tended to use additive and sequential types of linking adverbials than adversative and causal types. The results also showed that the students relied more heavily on a limited set of conjunctive adverbials and were not aware of the writing registers.
\end{abstract}

Index Terms - conjunctive adverbials, ESL learners, expository writing

\section{INTRODUCTION}

Conjunctive adverbials serve a connective function and make explicit the relationship between two units of discourse, rather adding additional information to a clause (Biber, et al., 1999). Proper and sensible use of conjunctive adverbials, and connecting ideas to enhance cohesion and coherence, may ease the process of understanding from the readers' perspective, but might be a difficult task and a potential problem for learners of English as a second language. Previous research showed that second language learners of English tend to overuse, underuse or misuse linking adverbials in second language writing (Milton and Tsang, 1993; Bolton, et al. 2002; Chen, 2006; Lei, 2012).

Previous research on conjunctive adverbials has been carried on among English learners from different language backgrounds, including French (Granger \& Tyson, 1996), Swedish (Altenberg \& Tapper, 1998), Korean (Yoon \& Yoo, 2011; Park, 2013), Chinese (Zhang, 2000; Chen, 2006; Lei, 2012). Zhang (2000) reported that Chinese undergraduate learners of English fail to construct logical and cohesive discourse, because they are found to have inadequate knowledge of logical connectors. Chen (2006) found that some conjunctive adverbials are overused, and some are not used appropriately, in MA TESOL students' writing. Lei (2012) claimed that Chinese linguistics doctoral students overuse, underuse and misuse adverbials in their doctoral dissertations.

However, little is known about how the postgraduate learners of different academic backgrounds in China are doing their writing, and what the causes of the potential problems are. This study compiled a learner corpus of 365 pieces of postgraduate learners' writings for analysis. It aims to work out the overall frequency of conjunctive adverbials, based on Celce-Murcia and Larsen-Freeman's taxonomy. Built on the quantitative data, qualitative analysis will be conducted to investigate the reasons behind the overall situation of the problem found in the investigation process.

\section{LITERATURE REVIEW}

\section{A. Definition and Taxonomy of Conjunctive Adverbials}

Previous research on adverbials serving the purposes of linking discourse have adopted different terms as "conjunctive adjuncts" (Halliday \& Hasan, 1976), "adverbial conjuncts" (Yeung, 2009), "linking adjuncts" (Carter \& McCarthy, 2006), "connectives” (Sanders et al., 2007), "linking adverbials" (Conrad, 1999; Biber et al., 1999; Lei, 2012; Yin, 2015), conjunctive adverbials (Chen, 2006). Though these terms may not overlap completely with each other, what the terms refer to are basically cohesive devices, specifying the relationship among sentences, hanging together the semantically related clauses (Celce-Murcia \& Larsen-Freeman, 1999).

Celcer-Murcia and Larsen-Freeman classified these cohesive devices into three types - coordinating conjunctions, adverbial subordinators, and conjunctive adverbials (e.g. therefore, however and thus). This paper will adopt the term "conjunctive adverbials", classified by Celcer-Murcia and Larsen-Freeman as one type of the cohesive devices.

Celce-Murcia and Larsen-Freeman, based on Halliday and Hasan's (1976) classification, simplified and divided conjunctive adverbials into the four types: additive, adversative, causal and temporal (1999), as is shown in Table 1. 
TABLE 1.

CELCE-MuRCIA AND LARSEN-FREEMAN'S TAXONOMY OF CONJUNCTIONS (1999, P.530)

\begin{tabular}{|l|l|}
\hline \multirow{4}{*}{ Additive } & Emphatic: in addition, moreover, furthermore, besides, also \\
\cline { 2 - 2 } & Appositional: that is, in other words, for instance \\
\cline { 2 - 2 } & Comparative: likewise, similarly \\
\hline \multirow{4}{*}{ Adversative } & Proper adversative: however, nevertheless, despite this, in contrast \\
\cline { 2 - 2 } & Contrastive: in fact, actually, however, on the other hand, at the same time \\
\cline { 2 - 2 } & Correction: instead, rather, on the contrary, at least \\
\cline { 2 - 2 } Causal & Dismissal: in any case, anyhow, at any rate \\
\hline Sequential & General causal: therefore, consequently, for that reason, thus \\
\cline { 2 - 2 } & Causal conditional: then, in that case, otherwise \\
\hline
\end{tabular}

\section{B. Previous Studies}

The investigation of cohesive devices started from the publication of Halliday and Hasan's Cohesion in English in 1976. In the 1990s, with the development of corpus linguistics, more and more experimental and corpus-based studies have narrowed down their research focus specifically to 'connectors', and herein conjunctive adverbials adopted by the present study. Therefore, research of connective conjunctions in ESL context will be reviewed.

Milton and Tsang (1993) compared the use of logical connectors in Hong Kong students' writing in a four-million-word learner corpus in Hong Kong University of Science and Technology, with that of three native corpora: the Brown Corpus, the London Oslo/Bergen Corpus, and another self-compiled corpus of computer science textbooks. They claimed that students tend to overuse some logical connectors in their writing. Quantitative results show that frequently overused connectors were sequential (eg. lastly, secondly, firstly), additive (eg. besides, moreover, furthermore), causal (eg. consequently, therefore). Their further qualitatively analyzed the usage of moreover and therefore and they claimed that students' difficulty lay in redundant use and misuse.

Granger and Tyson (1996) compared the frequency of connector usage in a French sub-corpus of the International Corpus of Learner English (ICLE) with a comparable native speaker corpus, the Louvain Corpus of Native Essay Writing (LOCNESS). Their result suggested that of the investigated 108 connectors, connectors like however and therefore were underused, while moreover and for instance, and on the contrary are overused. The students' misuse of some connectors were credited to their insensitiveness to the style of writing, and suggested that stylistics needed to be addressed in writing class.

Altenberg and Tapper (1998) examined the use conjuncts in Swedish students' writing by compiling 86 learners' untimed essays. The Swedish learner corpus was compared with a control native speaker corpus consisting of 70 essays by third and fourth year students from the University of Surrey, England. Their hypothesis that advanced Swedish learners of English tended to underuse linking adverbials in their writing, was supported by the quantitative results. Their further qualitative analysis suggested that students tended to overuse some conjuncts (e.g. moreover, for instance and on the contrary), and to underuse some conjuncts (e.g. hence, therefore, thus and however). Further analysis revealed that the underuse of some conjuncts were due to students' unawareness of the register in the target language. Swedish learners tended to use the informal words (e.g. but) rather than the appropriate formal alternatives (Altenberg \& Tapper, 1998, p.91). Hence, register awareness in teaching writing was recommended in their research.

Bolton et al. (2002) examined the frequency of use of connectors in three sets of data, part of Hong Kong component of the International Corpus of English (ICE-HK), the corresponding data from the British component of the International Corpus of English (ICE-GB), and data from a subset of published academic writing taken from ICE-GB. They reported that both non-native and native learners tend to overuse connectors than professional writers.

Chen (2006) investigated the use of conjunctive adverbials in MA students' writing in Taiwan. The author compiled a learner corpus with 23 MA TESOL students' final papers, and compared learner corpus with control corpus, with a selection of 10 journal articles from two top international TESOL journals. Results showed that the students overuse some conjunctive adverbials slightly and inappropriately.

Yoon and Yoo (2011) focused error analysis of English conjunctive adjuncts in Korean college students' writing, by analyzing a learner corpus of 102,632 words written by 399 Korean college freshmen. The results showed that Korean English learners preferred to use sentence-initial coordinators, even when not appropriate. Also, sentence fragments account for the most frequently made grammar mistakes in sentence writing. Finally, correct use of punctuation marks is another problem.

Lei (2012) examined Chinese doctoral students' use of linking adverbials in their academic writing. The comparison is also based on two self-compiled corpora. The learner corpus contains 20 applied linguistics doctoral dissertations. The control corpus is made up of 120 journal articles in six international applied linguistics journals. The study found that the Chinese doctoral students overused and underused linking adverbials and misused some of the linking adverbials (e.g. besides). The most problematic linking adverbials for the doctoral students were the adversative adverbials. Furthermore, the students relied on a limited set of linking adverbials in writing.

Liu (2013) explored the Chinese EFL learners' mental processes in the use of adversative, causal and temporal logical connectors in writing, and dipped further into the factors influencing the writers' choices of the logical connectors. The author reported that students would think in Chinese before they established a logical concept and 
chose one from several available repertoire of linking adverbials.

Leedham and Cai (2013) adopted a corpus approach to study both Chinese and British students' writing in UK universities. They found that Chinese ESL students tended to overuse adverbials, like besides, on the other hand, than their British counterparts. They argued that Chinese students preferred to use sentence-initial adverbials, and favored some particular linking adverbials and had little awareness of the register of writing.

Park (2013) studied how Korean EFL students use conjunctive adverbials in argumentative writing. The author divided the learner corpora into three different subcorpora based on students' English proficiency levels, and compared them with a reference corpus of American students' writings. The results revealed that all different levels of English learners overused conjunctive adverbials in their writing. Sequential and additive types were more overused, accounting for six times more than those of native writers. Moreover, sentence-initial adverbials were more used by learners, especially by the lowest-level learners.

Ha (2016) is almost the most updated study in linking adverbials in ESL context. The author explored the frequency and usage patterns of linking adverbials in Korean English writing, by comparing them with American LOCNESS sub-corpus. She compiled a corpus of 105 essays written by first-year university students in Korea. The author found that the distribution of different semantic categories was similar in both groups, but Korean learners exhibited a tendency of overuse of adverbials in writing. Noticeably, Korean English learners overuse sequential and additive categories of adverbials.

Crossley et al. (2016) is another by far the most updated and relevant study in cohesive devices and L2 writing. They assessed the development of cohesion development in L2 writers and investigated relationship between the use of cohesive devices and the judgments of L2 writing quality. They found that L2 learners' cohesion of writing might develop during one semester of learning.

All the above-reviewed studies claim that second language learners tend to "over/under/misuse" linking adverbials. When the terms such as "over/under/misuse" are used in previous literature, they indicate that there is a bench mark against which the frequency of linking adverbials should be examined, but which frequency standard should be the ideal model remains a question.

\section{Methodology}

The present study aims to investigate the use of conjunctive adverbials in English essay writing, by postgraduate learners from different academic backgrounds in Dalian University of Technology. It intends to find out how the English learners would use the conjunctive adverbials by compiling a learner corpus of 365 essays. It is hypothesized that the learners of English may use some certain groups of conjunctive adverbials inappropriately. Then the causes of the improper use might be investigated.

\section{A. Data Collection}

The participants in the present study are postgraduate learners of English, all placed in Reading and Writing class, but grouped into six different classes based on their availability during the time of English lectures. There are approximately 30-32 learners in each English class. They are all first-year postgraduate learners and have all passed the National English Test Band 4. They come from different academic backgrounds, and English is a compulsory course for the first-year postgraduate learners.

The teacher assigned two topics and asked them to finish up writing in an online writing lab within deadline of two weeks for each essay. The first topic was "Media and Culture" and students were required to write 100-150 words and illustrate their point of views. The second topic was "Do you think it is important to spend time and money on looking good? Why or why not?" and students were required to write no less than 100 words and illustrate their point of views. The essay writing process was quite independent and the participants might choose anytime that fits their time schedule. There were altogether 182 and 183 writings collected for the first and second topic respectively.

\section{B. Identification and Taxonomy of Conjunctive Adverbials}

Corpus analysis toolkit AntConc was used to analyze the text and Celce-Murcia and Larsen-Freeman's taxonomy of conjunctions (1999) was adopted to explore the use of each category of conjunctive adverbials. All the conjunctive adverbials and concordances were extracted from the text using AntCorc. Raw frequency of each category of conjunctive adverbials was calculated, reported and analyzed based on the four logical functions, namely additive, adversative, causal and sequential, in the text.

\section{ReSUlTS AND DisCUSSION}

Based on Celce-Murcia and Larsen-Freeman's taxonomy of conjunctions (1999), with a few more adverbials identified from the learners' writing, altogether, there were 44 conjunctive adverbials identified and calculated with AntConc. The hits of each conjunctive and the total hits of each subtype of conjunctive adverbials were calculated and reported in Appendix I.

Further analysis of the data revealed that the participants in the study used more additive and sequential conjunctives, with a total of 500 hits and 444 hits respectively, which accounted for larger percentage of use than the other two types. 
Adversative conjunctive adverbials accounted for 208 hits, and causal 104 hits. The percentage of each type and the subtypes among the total identified conjunctive adverbials was shown in Table 2.

TABLE 2.

PERCENTAGE OF USE OF CONJUNCTIVE ADVERBiALs By CATEGORY

\begin{tabular}{|c|c|c|c|c|c|}
\hline Types of CA & Total Hits & Percentage & Subtypes & Hits & Percentage \\
\hline \multirow{3}{*}{ Additive } & \multirow{3}{*}{500} & \multirow{3}{*}{$39.81 \%$} & Emphatic & 400 & $31.85 \%$ \\
\hline & & & Appositional & 97 & $7.72 \%$ \\
\hline & & & Comparative & 3 & $0.24 \%$ \\
\hline \multirow{4}{*}{ Adversative } & \multirow{4}{*}{208} & \multirow{4}{*}{$16.56 \%$} & Proper adversative & 96 & $7.64 \%$ \\
\hline & & & Contrastive & 64 & $5.10 \%$ \\
\hline & & & Correction & 48 & $3.82 \%$ \\
\hline & & & Dismissal & 0 & $0.00 \%$ \\
\hline \multirow{2}{*}{ Causal } & \multirow{2}{*}{104} & \multirow{2}{*}{$8.28 \%$} & General causal & 80 & $6.37 \%$ \\
\hline & & & Causal conditional & 24 & $1.91 \%$ \\
\hline Sequential & 444 & $35.35 \%$ & Sequential & 444 & $35.35 \%$ \\
\hline
\end{tabular}

\section{A. Most Frequently Used Conjunctive Adverbials in Learner Corpus}

Among the highly frequently used conjunctive adverbials, the additive and sequential subtypes together constitute $75.16 \%$ of the total. Further calculation of the most used adverbials showed that the 10 most frequently used conjunctive adverbials accounted for $70.86 \%$ of the total, which were listed in Table 3.

TABLE 3.

TOP 10 MOST FREQUENTLY USED CAS IN LEARNER CORPUS

\begin{tabular}{|l|l|l|l|}
\hline CA & Hits & Percentage & Type \\
\hline also & 279 & $22.21 \%$ & additive \\
\hline first(ly) & 179 & $14.25 \%$ & sequential \\
\hline however & 82 & $6.53 \%$ & adversative \\
\hline for example & 73 & $5.81 \%$ & additive \\
\hline last(ly) & 71 & $5.65 \%$ & sequential \\
\hline then & 45 & $3.58 \%$ & sequential \\
\hline second(ly) & 44 & $3.50 \%$ & sequential \\
\hline therefore & 43 & $3.42 \%$ & causal \\
\hline finally & 38 & $3.03 \%$ & sequential \\
\hline on the other hand & 36 & $2.87 \%$ & adversative \\
\hline
\end{tabular}

Noticeably, "also" was mostly used to show additive relationship between different units of language, either in initial or middle positions in texts. Furthermore, the result also revealed that students tended to use "first(ly)", "second(ly)", "then", "last(ly)", "finally" to set up the sequential relationship in their writing. Among adversative conjunctive adverbials, "however" and "on the other hand" were most preferred. Only one causal type adverbial "therefore" was on the list of most frequently used conjunctive adverbials. The result echoed Chen's study in 2006 that students would rely on a limited set of conjunctive adverbials in creating the discourse.

\section{B. Least Frequently Used Conjunctive Adverbials in Learner Corpus}

In contrast to the most frequently used ones, the least frequently used conjunctive adverbials were calculated. Among the additive category, "additionally", "in fact", "that is", "in other words", "similarly" were least found in students" writing. To show the adversative aspect, students rarely used "in/by contrast", "instead", "at least". "Consequently" and "in that case" were least used causal type. Due to high reliance on some previously found highly frequently used sequential type, "next" and "to conclude" were found with lower frequency.

Beside, several conjunctive adverbials, namely "likewise", "despite this", "in any case", "anyhow", "at any rate", "for that reason", "up to now", were never found in students' writing, as classified and listed by Celce-Murcia and Larsen-Freeman (1999).

The least frequently used conjunctive adverbials, with hits from 0 to 4 out of the 1256 hits altogether, amounted to 20 , which outnumbered the top 10 most frequently used ones. Again, this revealed that students would prefer to choose the most popular and acquainted set of conjunctive adverbials in their word repertoire.

\section{Learner Corpus Analysis}

Previous research claimed that second language learners tended to overuse, underuse or misuse linking adverbials in second language writing (Milton and Tsang, 1993; Bolton, et al. 2002; Chen, 2006; Lei, 2012), usually based on the comparison of corpora between native speakers and non-natives. However, Chen (2006) argued that there was no precise definition of "overuse" or "underuse". Therefore, this study will explore the use of some most and least preferred conjunctive adverbials by the learners, and hopefully the findings might shed light on the teaching practice.

Based on the calculation of the most and least frequently used conjunctive adverbials, further detailed analysis needed to be carried out to see how students construct the discourse. Excerpts of some students' writing were taken for detailed examination. 


\section{Learner corpus Excerpt 1}

Along with computer technology unceasing development, the various media playing a main role in enriching people's acceptable information resources has contributed to a great change in our life.

First of all, the media have changed the way of contact between people. Secondly, the media broaden the personal information and expand the personal knowledge. Convenient platform, massive information and timely updates allow each individual to be involved in the whole world. Various categories of media make us gain an insight into what we are interested in quickly. Besides, the media accelerate the process of democratization in our country and the solution of social problems. Individuals are free to express their opinions on the incident which can have an impact on the behavior of decision makers. Finally, the media enrich the cultural life of the individual. We can enjoy our leisure by watching a variety of cultural products, from the show to the Opera.

In short, the rise and development of the media affect all aspects of individual life. Only we improve the ability of our own judgment, can we receive a good influence.

Generally, Excerpt 1 is a typical example of most of the students' writing. The first paragraph introduces the point of view of the writer and the last paragraph is an echo of the introductory paragraph. The body paragraph typically consists of two to four supporting ideas, listed by sequential adverbials "first/firstly/first of all", "second/secondly, third/thirdly", "finally/lastly" etc., as calculated as most frequently used adverbials in learners' writing. The conclusion paragraph ends with "in a word", which is more informal than formal. This echoed previous studies which claimed that students should be instructed to be aware of the writing register differences (Granger \& Tyson, 1996; Chen, 2006).

Learner corpus Excerpt 2

The love for beauty is common to all men. Nowadays, in order to become beautiful, more and more people like to dress themselves. Looking good is not just women's patents. I think it is important to spend time and money on looking good.

First of all, social environment makes people pay more attention to outward appearance. In the modern society, young and beautiful become a kind of wealth, which can create opportunities and advantages in the competition. Secondly, pursuing beautiful is people's inner needs. Physical beauty through dressing can obtain immediately, and it can satisfy people's craving. Thirdly, looking good can enhance self-confidence, experience happiness, and conducive to success. The last and the most important is that looking good can attract girls' or boys' attention, getting more job opportunities. Even though it is important to look good, we shouldn't spend much more money or time on that. On the one hand, as a method to become beautiful, plastic surgery is risky. Examples of plastic failure are countless, some of which lost their lives, this is a tragedy indeed. On the other hand, as a student, if we spend a lot of energy on dressing ourselves, it is not conducive to our study.

In a word, the physical beauty can make us more confident to face the difficulties in our lives. It can strengthen our hearts and makes us happier lives. So it is important to spend time and money on looking good.

Generally, Excerpt 2 also exhibits a commonly used structure of expository essays, with the introductory, body and conclusion paragraphs. In the three-paragraph writing, 7 conjunctive adverbials are used, with 5 belonging to sequential type, and 2 adversative type. The sequential adverbials, are used in the body paragraph to list and link the supporting ideas. However, in the second part of the body paragraph, the writer switched to the opposite opinion that "Even though it is important...", and adopted the adversative conjunctive adverbials "on the one hand" and "on the other hand" to link his/her points. According to the definition in Cambridge Dictionary, "on the one hand" and "on the other hand" are used to "compare two different facts or two opposite ways of thinking about a situation", but the two points the writer included are not contrastive, but additive. "In a word" is again used in this conclusion paragraph, which is quite common in learners' writing.

\section{CONCLUSION AND PRACTICAL IMPLICATIONS}

The present research studied the use of conjunctive adverbials in expository writings by postgraduate learners from different academic backgrounds in Dalian University of Technology. The results showed that learners used a total of 44 different conjunctive adverbials, belonging to 4 types as classified by Celce-Murcia and Larsen-Freeman's (1999), in their writings.

The data revealed that the participants in the study used more additive and sequential conjunctives, 500 hits and 444 hits respectively, than adversative conjunctive and causal adverbials, with 208 and 104 hits. Among the highly frequently used conjunctive adverbials, the additive and sequential subtypes together constitute $75.16 \%$ of the total.

Remarkably, "also" was mostly used to show additive relationship between different units of language. Furthermore, the sequential conjunctive adverbials, e.g. "first(ly)", "second(ly)", "then", "last(ly)", "finally", were highly preferred in students' writings. Among adversative conjunctive adverbials, "however" and "on the other hand" were most preferred, with a proportion of misuse with "on the other hand". "Therefore" was the only one causal type of adverbial detected in writing samples, on the list of most frequently used conjunctive adverbials. Contrastively and noticeably, conjunctive adverbials like "likewise", "despite this", "in any case", "anyhow", "at any rate", "for that reason", "up to now", were never found in students' writing, as listed by Celce-Murcia and Larsen-Freeman (1999).

The sample analysis of the learners' writings showed that they commonly used structure of expository essays, with the introductory, body and conclusion paragraphs. The body paragraph typically adopted sequential adverbials as links 
of discourse. However, the conclusion paragraph ends with "in a word", which is more informal than formal.

The results showed that learners would rely on a limited set of conjunctive adverbials in creating the discourse and. Furthermore, the learners are not conscious of the writing register differences, and thus choosing inappropriate adverbials in their writing. Therefore, in teaching practice, learners should be exposed to quantity of appropriate use of conjunctive adverbials, and register awareness should be raised explicitly in instruction.

For future research, and for more practical teaching implications for EFL practitioners, larger-scale corpus-based studies on EFL learners' essay writings should be carried out to gain a more comprehensive look at the learners' writing and academic exchange capability.

\section{APPENDIX}

\section{Conjunctive Adverbials in Learner Corpus}

\begin{tabular}{|c|c|c|c|c|}
\hline Types of CAs & Subtypes & Total Hits & Conjunctive Adverbials & Hits \\
\hline \multirow{14}{*}{ Additive } & \multirow{8}{*}{ Emphatic } & \multirow{8}{*}{400} & in addition & 28 \\
\hline & & & additionally & 3 \\
\hline & & & moreover & 19 \\
\hline & & & furthermore & 8 \\
\hline & & & besides & 32 \\
\hline & & & also & 279 \\
\hline & & & at the same time & 28 \\
\hline & & & in fact & 3 \\
\hline & \multirow{4}{*}{ Appositional } & \multirow{4}{*}{97} & that is (to say) & 4 \\
\hline & & & in other words & 3 \\
\hline & & & for instance & 17 \\
\hline & & & for example & 73 \\
\hline & \multirow{2}{*}{ Comparative } & \multirow{2}{*}{3} & likewise & 0 \\
\hline & & & similarly & 3 \\
\hline \multirow{16}{*}{ Adversative } & \multirow{5}{*}{ Proper adversative } & \multirow{5}{*}{96} & however & 82 \\
\hline & & & nevertheless & 7 \\
\hline & & & despite this & 0 \\
\hline & & & in contrast & 4 \\
\hline & & & by contrast & 3 \\
\hline & \multirow{4}{*}{ Contrastive } & \multirow{4}{*}{64} & in fact & 8 \\
\hline & & & actually & 13 \\
\hline & & & on the other hand & 36 \\
\hline & & & at the same time & 7 \\
\hline & \multirow{4}{*}{ Correction } & \multirow{4}{*}{48} & instead & 2 \\
\hline & & & rather & 28 \\
\hline & & & on the contrary & 17 \\
\hline & & & at least & 1 \\
\hline & \multirow{3}{*}{ Dismissal } & \multirow{3}{*}{0} & in any case & 0 \\
\hline & & & anyhow & 0 \\
\hline & & & at any rate & 0 \\
\hline \multirow{8}{*}{ Causal } & \multirow{5}{*}{ General causal } & \multirow{5}{*}{80} & therefore & 43 \\
\hline & & & consequently & 3 \\
\hline & & & for that reason & 0 \\
\hline & & & thus & 27 \\
\hline & & & as a result & 7 \\
\hline & \multirow{3}{*}{ Causal conditional } & \multirow{3}{*}{24} & then & 8 \\
\hline & & & in that case & 2 \\
\hline & & & otherwise & 14 \\
\hline & & & first (firstly) & 179 \\
\hline & & & then & 45 \\
\hline & & & next & 3 \\
\hline & & & second (secondly) & 44 \\
\hline & & & third (thirdly) & 12 \\
\hline & & & last & 71 \\
\hline Sequential & Sequential & 444 & finally & 38 \\
\hline & & & up to now & 0 \\
\hline & & & to sum up & 8 \\
\hline & & & in conclusion & 11 \\
\hline & & & to conclude & 4 \\
\hline & & & in summary & 6 \\
\hline & & & all in all & 23 \\
\hline
\end{tabular}

\section{REFERENCES}

[1] Altenberg, B. \& Tapper, M. (1998). The use of adverbial connectors in advanced Swedish learners' written English. In S. 
Granger (Ed.), Learner English on Computer (pp. 80-93). Harlow: Addison Wesley Longman Limited.

[2] Biber, D., S. Johansson, G. Leech, S. Conrad \& E. Finegan. (1999). Longman Grammar of Spoken and Written English. London: Longman.

[3] Bolton, K., Nelson, G. \& Hung, J. (2002). A corpus-based study of connectors in student writing: Research from the international corpus of English in Hong Kong (ICE-HK). International Journal of Corpus Linguistics, 7(2), 165-182.

[4] Carter, R. \& McCarthy, M. (2006). Cambridge grammar of English. Cambridge, New York: Cambridge University Press.

[5] Celce-Murcia, M. \& Larsen-Freeman, D. (1999). The Grammar Book: An ESL/EFL Teacher's Course (2 ${ }^{\text {nd }}$ ed). Boston: Heinle \& Heinle Publishers.

[6] Chen, C. (2006). The use of conjunctive adverbials in academic papers of advanced Taiwanese EFL learners. International Journal of Corpus Linguistics, 11(1), 113-130.

[7] Conrad, S. (1999). The importance of corpus-based research for language teachers. System: 27(1), 1-18.

[8] Crossey, S., Kyle, K. \& McNamra, D. (2016). The development and use of cohesive devices in L2 writing and their relations to judgments of essay quality. Journal of Second Language Writing, 32, 1-16.

[9] Granger, S. \& Tyson, S. (1996). Connector usage in the English essay writing of native and non-native EFL speakers of English, World Englishes, 15(1), 17-27.

[10] Ha, M. (2016). Linking adverbials in first-year Korean university EFL learners' writing: a corpus-informed analysis. Computer Assisted Language Learning, 29 (6). 1090-1101.

[11] Halliday, M. \& Hasan, R. (1976). Cohesion in English. New York: Longman.

[12] Milton, J., \& Tsang, E. (1993). A corpus-based study of logical connectors in EFL students' writing: Directions for future research. In R. Pemberton \& E. Tsang (Eds.), Lexis in studies (pp. 215-246). Hong Kong University Press.

[13] Leedham, M. \& Cai, G. (2013). Besides...on the other hand: Using a corpus approach to explore the influence of teaching materials on Chinese students' use of linking adverbials. Journal of Second Language Writing, 22, 374-389.

[14] Lei, L. (2012). Linking adverbials in academic writing on applied linguistics by Chinese doctoral students. Journal of English for Academic Purposes, 11, 267-275.

[15] Liu, Y. (2013). A study of Chinese university students' usage of logical connectors in English argumentations, descriptions and arrations. The Asian Conference on Language Learning. Osaka, Japan.

[16] Park, Y. (2013). How Korean EFL students use conjunctive adverbials in argumentative writing. English Teaching, 68 (4), 263-284.

[17] Sander, T., Land, J. \& Mulder, G. (2007). Linguistic markers of coherence improve text comprehension in functional contexts. Information Design Journal, 15(3), 219-235.

[18] Yeung, L. (2009). Use and misuse of 'besides': A corpus study comparing native speakers' and learners' English. System, 37. 330-342.

[19] Yin, Z. (2015). The use of cohesive devices in News Language: overuse, underuse or misuse? RELC Journal, 46(3), 309-326.

[20] Yoon, J. \& Yoo, I. (2011). An error analysis of English conjunctive adjuncts in Korean college students' writing. English Teaching, 66 (1), 225-244.

[21] Zhang M. (2000). Cohesive Features in the Expository Writing of Undergraduates in Two Chinese Universities. RELC Journal, $31(1), 61-95$

Xuehua An was born in February 1979, in Jilin Province in China. She majored in linguistics and got her BA and MA in Dalian University of Technology, in 2002 and 2009 respectively. Her research interests include second language writing, English for Academic purposes. She is currently an Associate Professor in Dalian University of Technology.

Mingying Xu was born in November 1977 in Heilongiiang Province in China. She majored in American Literature and got her $\mathrm{PhD}$ in 2013 at Shanghai Foreign Languages University. Her research interests include American literature, second language acquisition. She is an Associate Professor in Dalian University of Technology and teaches English as a second language to students from intermediate to advanced level. 